\title{
Development and validation of the Beliefs and Behaviour Questionnaire (BBQ)
}

\author{
Johnson George $^{\mathrm{a}}$, Andrew Mackinnon ${ }^{\mathrm{b}}$, David C.M. Kong ${ }^{\mathrm{a}}$, Kay Stewart ${ }^{\mathrm{a}, *}$ \\ ${ }^{a}$ Department of Pharmacy Practice, Victorian College of Pharmacy, Monash University, Parkville, Australia \\ ${ }^{\mathrm{b}}$ Centre for Mental Health Research, Australian National University, Canberra, ACT, Australia
}

Received 22 March 2005; received in revised form 9 September 2005; accepted 11 November 2005

\begin{abstract}
Objective: To develop and validate a questionnaire to screen for potential nonadherence in patients with chronic ailments.

Methods: Themes from qualitative interviews with chronic obstructive pulmonary disease patients were used in developing content of the questionnaire. The questionnaire was distributed to 525 ambulatory patients with chronic lung diseases. Principal components analysis was performed to identify the subscales in the questionnaire. Internal consistency, validity and stability of the subscales were also evaluated. Results: The 30-item Beliefs and Behaviour Questionnaire (BBQ) measures beliefs, experiences and adherent behaviour on five-point Likerttype scales. Two hundred and eighty patients $(53.3 \%)$ with a mean age of 71.1 years responded to the questionnaire. The 'beliefs' section had a two-factor solution-'confidence' and 'concerns' with internal consistencies of 0.82 and 0.45 , respectively. The two domains identified from the section 'experiences'-satisfaction' and 'disappointment' had internal consistencies of 0.85 and 0.52 , respectively. The 'behaviour' section, separately entitled the Tool for Adherence Behaviour Screening (TABS), had a two-factor solution- 'adherence' and 'nonadherence', with internal consistencies of 0.80 and 0.59 , respectively. All the domains demonstrated comparable reliabilities across two different patient populations. Their temporal stabilities ranged between 0.62 and 0.94 .

Conclusion: The validity, reliability and utility of the BBQ and the TABS, a sub-scale of the BBQ that screens both intentional and unintentional nonadherence to pharmacological and non-pharmacological disease management, have been established.

Practice implications: The BBQ and the TABS have potential applications in screening adherence beliefs, experiences and behaviour in both clinical practice and research.

(C) 2005 Elsevier Ireland Ltd. All rights reserved.
\end{abstract}

Keywords: Adherence; Beliefs; Behaviour; Management; Tool

\section{Introduction}

Patient adherence to physicians' recommendations is the key intermediary between medical practice and patient outcomes [1]. Adherence to recommended treatment for different disease conditions in various settings is known to be approximately 50\% [2]. Adherence to non-pharmacological management (e.g. lifestyle changes such as diet, exercise, and smoking cessation) is known to be the most

\footnotetext{
* Corresponding author at: Department of Pharmacy Practice, Victorian College of Pharmacy, Monash University, 381 Royal Parade, Parkville, Vic. 3052, Australia. Tel.: +61 39903 9618; fax: +61 399039629 .

E-mail address: Kay.Stewart@vcp.monash.edu.au (K. Stewart).
}

difficult for patients [3]. Nonadherence continues to be a major source of frustration for health professionals and an impediment to achievement of therapeutic goals [4].

The nature, extent and determinants of nonadherent behaviour are complex. There are no theories of adherence per se, but various models and theories such as Health Belief Model [5], Locus of Control Theory [6], and Self-regulatory Model [7] have been used to predict the variability that characterizes behavioural adherence. Despite extensive research, limited understanding of adherence phenomena and the absence of a standard theoretical framework suitable for all populations for empirically testing adherence outcomes against the determinants are common problems in adherence research [8]. Based on an extensive review of 
the literature on socio-psychological and related variables which have proven to be consistent predictors of compliance and patient acceptance of recommended health behaviours, Becker and Maiman [9] constructed a theoretically driven model for predicting and explaining compliance (adherence) behaviour with health and medical care recommendations.

Patient self-report using reliable and valid questionnaires is the most efficient and cost-effective method of assessing adherence and related beliefs and attitudes [10-13]. From the clinician's point of view, self-reports are the most viable and useful measures of adherence [14], as they can identify the reasons behind nonadherence along with its detection, which could then help in rectifying or addressing those underlying issues. Self-report when combined with clinical observation has been shown to have better sensitivity than self-report alone [15]. Various self-report tools have been used for studying adherence behaviours and associated health beliefs and attitudes in both general and specific patient populations [15-30]. The most commonly used measures of adherence are Morisky scale [16], the Medication Adherence Report Scale (MARS) [17] and the Brief Medication Questionnaire (BMQ) [18]. Weinman et al. [29] developed the Illness Perceptions Questionnaire to fit with Leventhal's description of illness representation for assessing the cognitive representation of illness. Horne et al. [30] developed the Beliefs about Medicines Questionnaire to quantify patients' personal beliefs about the necessity of their prescribed medication and their concerns about taking it. The correlations between patient beliefs about prescribed medications and self-reported adherence were in the predicted direction in a cross-sectional study of patients with various chronic diseases [13].

Patients may exhibit different types of nonadherent behaviour. Unintentional nonadherence may be due to forgetfulness, or inability to follow treatment instructions due to poor understanding or physical problems such as poor eyesight or dexterity, whereas intentional nonadherence arises when the patient rejects either the doctor's diagnosis or the doctor's recommended treatment [31,32]. The latter is often based on a patient's rational decision and has been called 'intelligent nonadherence' [33]. Previous studies have recognised the importance of screening for both intentional and unintentional nonadherence when adherence assessments are being made [21,34]; however, it is critical that a single scale measures a single construct or characteristic [35]. Commonly used adherence screening instruments such as Morisky's scale compound the two facets of nonadherence - intentional and unintentional nonadherence - in one scale [34].

No single tool is available for measuring the different health beliefs and adherent behaviours with regard to both pharmacological and non-pharmacological management in patients with chronic ailments. Kravitz and Melnikow [1] have highlighted the need for new adherence metrics, especially those capable of screening patient's behaviours. Nonadherence is a multifactorial health behaviour, which can be best understood only within the patient's physical, economic, psychological and social considerations. In-depth interviews with subjects who are representative of the population of interest is an ideal way of generating credible and highly face-valid items for inclusion in health care scales [36]. The Becker and Maiman model offers a suitable conceptual framework for predicting and explaining adherence behaviour with health and medical care recommendations. The aim of this study was to develop and validate a health beliefs and behaviour questionnaire for screening adherent behaviour in patients with chronic ailments.

\section{Methods}

\subsection{Development of the questionnaire}

The item pool for the questionnaire was generated from the themes pertaining to adherence identified through content and thematic analysis of in-depth interviews with 28 ambulatory patients with moderate to severe chronic obstructive pulmonary disease (COPD). A description of the interview sample is given elsewhere [37]. The identified themes were developed into simple statements and were grouped under three sections-beliefs, experiences and behaviours (practices), using the Becker-Maiman model as the theoretical framework. Items were worded both positively and negatively within the same section to avoid acquiescence, affirmation or agreement bias [36]. The number of response categories and their directions were kept uniform across the questionnaire to avoid patient confusion. The study had approval from the Monash University Standing Committee on Ethics in Research involving Humans.

\subsection{Face and content validation of the questionnaire}

Two clinical pharmacists with expertise in geriatrics and two health care researchers with experience in adherence research were asked to evaluate the relevance, clarity and conciseness of the items included in the questionnaire. The questionnaire was pilot tested on three patients with chronic respiratory ailments.

\subsection{Administration of the questionnaire to the validation sample}

Patients with chronic lung conditions were contacted through various respiratory support groups and one pulmonary rehabilitation centre in Victoria, Australia, for validating the questionnaire. Questionnaires were forwarded to the group leaders/coordinators who were requested to distribute them during regular group meetings or to mail them to the group members. Reminder letters were sent to all patients in the pulmonary rehabilitation database by the coordinator 4 weeks after the initial mail-out; due to the anonymous nature of the questionnaire, all patients were 
sent reminders. Leaders of respiratory support groups were requested to remind their group members about the questionnaire 4 weeks after the date of distribution of the questionnaire.

\subsection{Criterion and construct validation}

A self-reported measure of adherence whose validity had been previously established in several patient populations, the MARS, was included in the battery to assist in establishing the validity of the subscale(s) of the questionnaire assessing behaviour. The same response format as the MARS (five-point Likert-type scale) was intentionally chosen for the section on behaviour in the BBQ. Patients who have low scores for the item regarding forgetting to take medicine in the MARS are likely to be unintentionally nonadherent. On the other hand, patients who have low scores for the item regarding decision to miss out a dose in the MARS are likely to demonstrate 'intentional nonadherence'. Convergent validities of the components of the behaviour section were explored by testing their correlations with the above-mentioned items in the MARS. Discriminant validity of this section was tested by undertaking a principal components analysis on all the items in MARS and the section on behaviour. Convergent validities of the subscales in the BBQ were evaluated by examining their intercorrelations and correlations with the MARS.

\subsection{Stability testing}

Twenty patients who had provided their contact details on their responses to the questionnaire were approached after 4 weeks to complete it a second time, to test its temporal stability (test-retest reliability). The total sample was divided into two-subjects from various patient support groups and subjects from the pulmonary rehabilitation database and the internal consistency of the various subscales in the questionnaire were compared (split sample stability testing [36]).

\subsection{Data analysis}

Responses were entered into SPSS for Windows (version 11.5, SPSS Inc., Chicago). Principal components analysis was performed on the sections for beliefs, experiences and behaviour separately after confirming the suitability of the data for factor analysis by assessing the correlation matrix for multiple coefficients $\geq 0.3$, Kaiser-Meyer-Oklin value $>0.6$, and a significant $(p<0.05)$ Barlett's test of sphericity. The number of components to be retained was determined by inspection of the scree plot of eigenvalues. Orthogonal (Varimax) rotation was performed initially to aid in the interpretation of the components and the results were compared to oblique (Promax) rotation. Reliabilities of the domains (subscales) were assessed using Cronbach's alpha and item-total correlations.
Correlations between non-normally distributed variables were assessed using Spearman's $\rho$. The test-retest reliabilities (temporal stabilities) of the various sub-scales in the BBQ and the MARS were assessed using intraclass correlation coefficients (ICC).

\section{Results}

\subsection{Item characteristics}

The 30-item Beliefs and Behaviour Questionnaire (BBQ) was developed to reflect the 23 major themes pertaining to beliefs, experiences and adherence behaviours identified through the in-depth interviews. At least one item was developed and included for each major theme with the exception of the theme designated 'emotional'; based on information gained from the interviews, this theme was not included due to its 'short life' as a behaviour and its minimal impact on chronic medication use. One item was identified for the themes 'experimentation' and 'symptomatology' due to their close relationship. Some broader themes had more than one corresponding item in the BBQ.

The pilot sample of patients took approximately $8 \mathrm{~min}$ on average to complete the BBQ. Feedback from the pharmacists, researchers, and patients led to minor revisions in the wording and structuring of some items. The list of variables in the Becker-Maiman model and the corresponding themes from the interviews and items in the final version of the BBQ are shown in Table 1 .

\subsection{Participants}

A total of 525 questionnaires were distributed to patients; 280 responses were received $(53.3 \%$ response rate). Four responses had to be excluded due to considerable missing information (more than five items left unanswered). The 276 respondents, of whom $54.4 \%$ were male, had a mean age of $71.1 \pm 8.7$ years. They were using on average $7.6 \pm 4.1$ regular medications, and $3.2 \pm$ 3.6 prn (when necessary) medications. Complementary and alternative medicine use was self-reported by one-third $(32.7 \%)$ of the patients. COPD was the underlying disease condition in $90.6 \%$ of the respondents, while asthma (5.4\%), bronchiectasis (2.2\%) and others ([1.8\%], e.g. lung carcinoma, lungectomy) were the other respiratory conditions reported by the respondents. Two-thirds of the respondents had comorbid conditions. The total MARS scores among the respondents ranged between 10 and 25 and the mean score was $23.37 \pm 2.01$. High adherence (MARS score of 25) was reported by 102 patients, while 37 respondents had scores less than 20. Among the respondents, 222 answered all 14 items in the section on beliefs, 260 answered all eight items in the section on experiences and 258 answered all eight items in the section on behaviour of the BBQ. 
Table 1

Becker-Maiman model factors, interview themes and BBQ items

\begin{tabular}{|c|c|c|}
\hline Factors in Becker-Maiman model & Theme from the in-depth interviews & Item in the Beliefs and Behaviour Questionnaire \\
\hline \multirow[t]{2}{*}{ Motivations } & 1. Acceptance or denial of illness & 1. I have sufficient understanding about my illness \\
\hline & 2. Living with the disease/quality of life & $\begin{array}{l}\text { 2. I have sufficient understanding about the options } \\
\text { for managing my illness }\end{array}$ \\
\hline \multirow[t]{5}{*}{$\begin{array}{l}\text { Value of illness } \\
\text { threat reduction }\end{array}$} & 3. Prognosis & $\begin{array}{l}\text { 3. I know what to expect from my illness } \\
\text { management }\end{array}$ \\
\hline & 4. Knowledge about the treatment & 4. The management of my illness is a mystery for me \\
\hline & & 5. Using any medication involves some risk \\
\hline & & 6. Natural remedies are safer than medicines \\
\hline & 5. Embarrassment & 7. The management of my illness disrupts my life \\
\hline \multirow{3}{*}{$\begin{array}{l}\text { Probability that } \\
\text { compliant behaviour } \\
\text { will reduce the threat }\end{array}$} & 6. Faith in the health professionals & 8. My doctors are very knowledgeable \\
\hline & 7. Faith in the treatment/medications & $\begin{array}{l}\text { 9. My current management will keep } \\
\text { my illness at bay }\end{array}$ \\
\hline & & 10. I am receiving the best possible management \\
\hline
\end{tabular}

Demographic

Structural

Interaction

Enabling

Theme from the in-depth interviews

8. Financial issues

9. Medication regimen

10. Concerns about the treatment

11. Satisfaction with health professionals

12. Time with health professionals

13. Empathy

14. Control over management

15. Treatment response

16. Satisfaction with the treatment

17. Experimentation and 18. symptomatology

ikelihood of compliance with preventive health recommendations and prescribed regimens
Demographic information collected as part of the BBQ

11. Financial difficulties limit my access to the best healthcare 12. I am on too many medications

13. I am concerned about the side effects from my medications

14. I am satisfied with the information my doctors share with me 15. My doctors have limited management options to offer me

16. My doctors spend adequate time with me

17. My doctors are compassionate

18. I have a say in the way my illness is managed

19. My medications are working

20. It is helpful to know the experiences of others with similar illness as mine

21. It is unpleasant to use some of my medications

22. It is physically difficult to handle some of my medications

23. I vary my recommended management based on how I am feeling

24. I put up with my medical problems before taking any action 25. I push myself to follow the instructions of my doctors

26. I get confused about my medications

27. I make changes in the recommended management to suit my lifestyle

28. I ensure I have enough medications so that I do not run out

29. I have strict routines for using my regular medications

30. I keep my medications close to where I need to use them

\subsection{Domains and reliability}

Principal components analysis of the section on beliefs, found four components having eigenvalues exceeding 1.0. However, a scree plot suggested the retention of only two components for further investigation. Varimax rotation was performed to aid in the interpretation of these two components-one pertaining to patients' confidence in their disease management, and the other regarding patients' concerns about their disease management (Table 2). These domains (subscales) were labeled 'confidence' and 'concerns', respectively. The two-factor solution explained a total of $42.7 \%$ of the variance, with 'confidence' contribut- ing $30.2 \%$ and 'concerns' contributing $12.6 \%$ of the variance. The components 'confidence' and 'concerns' had internal consistencies (Cronbach's $\alpha$ ) of 0.82 and 0.45 , respectively. Item characteristics are shown in Table 3 . Exclusion of the two items with the least item-total correlation from 'concerns'- 'it is helpful to know the experiences of others with similar illness as mine' and 'natural remedies are safer than medicines'-resulted in only a marginal improvement in its internal consistency (0.48).

Only two components with eigenvalues exceeding 1.0 were revealed in principal components analysis of the section on experiences. The scree plot supported the 
Table 2

Rotated component matrix of the section-beliefs

\begin{tabular}{lr}
\hline Item & Component \\
\cline { 2 - 2 } & 1 Confidence \\
\hline I have sufficient understanding about my illness & 0.71 \\
I know what to expect from my illness management & 0.81 \\
My current management will keep my illness at bay & 0.66 \\
I am receiving the best possible management & 0.79 \\
The management of my illness is a mystery for me & -0.50 \\
It is helpful to know the experiences of others with similar illness as mine & 0.12 \\
Natural remedies are safer than medicines & -0.13 \\
My doctors have limited management options to offer me & -0.26 \\
My medications are working & 0.01 \\
Using any medication involves some risk & 0.09 \\
I am on too many medications & 0.38 \\
I have a say in the way my illness is managed & 0.16 \\
I have sufficient understanding about the options for managing my illness & -0.11 \\
My doctors are very knowledgeable & 0.13 \\
\hline
\end{tabular}

Table 3

Response to the section-beliefs

\begin{tabular}{|c|c|c|c|}
\hline Item & $N$ & Mean \pm S.D. & Item-total correlation \\
\hline \multicolumn{4}{|l|}{ Confidence } \\
\hline I have sufficient understanding about my illness & 274 & $4.43 \pm 0.60$ & 0.55 \\
\hline I know what to expect from my illness management & 271 & $4.37 \pm 0.65$ & 0.68 \\
\hline My current management will keep my illness at bay & 268 & $3.93 \pm 0.85$ & 0.51 \\
\hline I am receiving the best possible management & 266 & $4.43 \pm 0.72$ & 0.67 \\
\hline The management of my illness is a mystery for $\mathrm{me}^{\mathrm{a}}$ & 263 & $2.14 \pm 1.34$ & 0.42 \\
\hline My medications are working & 265 & $4.22 \pm 0.65$ & 0.57 \\
\hline I have a say in the way my illness is managed & 268 & $4.01 \pm 0.95$ & 0.44 \\
\hline I have sufficient understanding about the options for managing my illness & 274 & $4.17 \pm 0.74$ & 0.61 \\
\hline My doctors are very knowledgeable & 274 & $4.57 \pm 0.64$ & 0.45 \\
\hline \multicolumn{4}{|l|}{ Concerns } \\
\hline It is helpful to know the experiences of others with similar illness as mine & 273 & $4.35 \pm 0.92$ & 0.11 \\
\hline Natural remedies are safer than medicines & 267 & $2.49 \pm 0.94$ & 0.20 \\
\hline My doctors have limited management options to offer me & 262 & $3.20 \pm 1.36$ & 0.26 \\
\hline Using any medication involves some risk & 270 & $3.83 \pm 1.09$ & 0.31 \\
\hline I am on too many medications & 267 & $2.62 \pm 1.21$ & 0.32 \\
\hline
\end{tabular}

Definitely true $=5 ;$ mostly true $=4$; do not know $=3$; mostly false $=2$; definitely false $=1$.

a Item reverse scored.

decision to retain these two components for further investigation. Varimax rotation was performed to aid in the interpretation of these two components-one regarding patients' satisfaction about their management and the other regarding patients' disappointment about their management (Table 4). These components were labeled 'satisfaction' and 'disappointment', respectively. The two-factor solution explained a total of $53.0 \%$ of the variance, with 'satisfaction'

Table 4

Rotated component matrix of the section-experiences

\begin{tabular}{lrr}
\hline Item & Component & 2 Disappointment \\
\cline { 2 - 3 } & 1 Satisfaction & 0.64 \\
\hline I am concerned about the side effects from my medications & 0.11 & 0.07 \\
It is unpleasant to use some of my medications & -0.04 & 0.71 \\
It is physically difficult to handle some of my medications & 0.87 & -0.02 \\
I am satisfied with the information my doctors share with me & 0.90 & 0.04 \\
My doctors are compassionate & -0.21 & 0.36 \\
Financial difficulties limit my access to the best healthcare & 0.85 & -0.04 \\
My doctors spend adequate time with me & -0.03 & 0.54 \\
The management of my illness disrupts my life & & \\
\hline
\end{tabular}


Table 5

Response to the section-experiences

\begin{tabular}{|c|c|c|c|}
\hline Item & $N$ & Mean \pm S.D. & $\begin{array}{l}\text { Item-total } \\
\text { correlation }\end{array}$ \\
\hline \multicolumn{4}{|l|}{ Satisfaction } \\
\hline My doctors are compassionate & 273 & $4.18 \pm 1.07$ & 0.77 \\
\hline I am satisfied with the information my doctors share with me & 274 & $4.08 \pm 1.17$ & 0.59 \\
\hline My doctors spend adequate time with me & 271 & $4.16 \pm 1.04$ & 0.69 \\
\hline \multicolumn{4}{|l|}{ Disappointment } \\
\hline I am concerned about the side effects from my medications & 273 & $2.63 \pm 1.20$ & 0.31 \\
\hline It is unpleasant (e.g. taste, smell) to use some of my medications & 275 & $1.64 \pm 0.96$ & 0.40 \\
\hline It is physically difficult to handle some of my medications & 272 & $1.25 \pm 0.66$ & 0.38 \\
\hline Financial difficulties limit my access to the best healthcare & 272 & $1.87 \pm 1.35$ & 0.17 \\
\hline The management of my illness disrupts my life & 275 & $3.12 \pm 1.32$ & 0.28 \\
\hline
\end{tabular}

Extremely $=5$; quite a bit $=4 ;$ moderately $=3 ;$ slightly $=2 ;$ not at all $=1$.

Table 6

Rotated component matrix of the section-behaviour

\begin{tabular}{llr}
\hline Item & Component & 2 Nonadherence \\
\cline { 2 - 3 } & 1 Adherence & 0.37 \\
\hline I get confused about my medications & 0.22 & -0.22 \\
I have strict routines for using my regular medications & 0.89 & -0.24 \\
I keep my medications close to where I need to use them & 0.94 & -0.22 \\
I ensure I have enough medications so that I do not run out & 0.53 & 0.18 \\
I push myself to follow the instructions of my doctors & 0.21 & 0.78 \\
I make changes in the recommended management to suit my lifestyle & 0.20 & 0.80 \\
I vary my recommended management based on how I am feeling & 0.25 & 0.48 \\
I put up with my medical problems before taking any action & & \\
\hline
\end{tabular}

contributing $29.5 \%$ and 'disappointment' contributing $23.5 \%$. The components 'satisfaction' and 'disappointment' had internal consistencies of 0.85 and 0.52 , respectively. Item characteristics are shown in Table 5. The exclusion of the item with the lowest item-total correlation- 'financial difficulties limit my access to the best health care'marginally improved the internal consistency of 'disappointment' to 0.55 .

In principal components analysis of the section of the BBQ concerning behaviour-the Tool for Adherence Behaviour Screening (TABS)-only two components emerged with eigenvalues exceeding 1.0, together explaining $60.2 \%$ of the variance. These components had items regarding adherent and nonadherent behaviours and were labeled as 'adherence' and 'nonadherence', respectively. 'Adherence' contributed to $37.6 \%$ of the variance while $22.6 \%$ was contributed by 'nonadherence'. The scree plot supported the decision to retain only two components for further interpretation, for which Varimax rotation was used (Table 6). The internal consistency of 'adherence' was found to be 0.80 , while 'nonadherence' had an internal consistency of 0.59 . Item characteristics are shown in Table 7. Removal

Table 7

Response to the section-behaviour (TABS)

\begin{tabular}{llc}
\hline Item & $N$ & $\begin{array}{c}\text { Mean } \pm \text { S.D. } \\
\text { Item-total } \\
\text { correlation }\end{array}$ \\
\hline Adherence & & $4.59 \pm 1.04$ \\
I have strict routines for using my medications & 271 & $4.73 \pm 0.91$ \\
I keep my medications close to where I need to use them & 275 & $4.70 \pm 0.95$ \\
I ensure I have enough medications so that I do not run out & 272 & $3.77 \pm 1.58$ \\
I push myself to follow the instructions of my doctors & 271 & $1.44 \pm 0.72$ \\
Nonadherence & 272 & $2.18 \pm 1.29$ \\
I get confused about my medications & 273 & $1.96 \pm 1.20$ \\
I make changes in the recommended management to suit my lifestyle & 272 & $2.79 \pm 1.22$ \\
I vary my recommended management based on how I am feeling & 273 & 0.35 \\
I put up with my medical problems before taking any action & 0.48 \\
\hline
\end{tabular}

Always $=5 ;$ often $=4$; sometimes $=3$; rarely $=2$; never $=1$. 
Table 8

Spearman rank correlations between subscales in the BBQ and the MARS

\begin{tabular}{|c|c|c|c|c|c|c|}
\hline & Confidence & Concerns & Satisfaction & Disappointment & Adherence & Nonadherence \\
\hline Concerns & $-0.22^{* *}$ & & & & & \\
\hline Satisfaction & $0.43^{* * *}$ & -0.09 & & & & \\
\hline Adherence & 0.10 & -0.02 & $0.21^{* *}$ & 0.07 & & \\
\hline Disappointment & $-0.35^{* * *}$ & $0.45^{* * *}$ & -0.12 & & & \\
\hline Nonadherence & $-0.30^{* * *}$ & $0.30^{* * *}$ & $-0.18^{* *}$ & $0.30^{* * * *}$ & 0.09 & \\
\hline MARS & $0.24^{* * *}$ & $0.30^{* * *}$ & $0.21^{* *}$ & $-0.14^{*}$ & 0.09 & $-0.4^{* * *}$ \\
\hline
\end{tabular}

${ }^{*} p<0.05$.

** $p<0.01$.

**** $p<0.001$.

of the item with the least item-total correlation-'I get confused about my medications'-improved the internal consistency of 'nonadherence' only marginally (0.60), a dubious advantage given that such a change would transform the scale to one that solely portrays 'intentional nonadherence'. The items in 'adherence' also reflect the presence of behaviours that would avoid 'unintentional nonadherence'. Of the respondents, 266 answered all the items on MARS. The MARS exhibited a moderate internal consistency of 0.66 in this sample of patients.

\subsection{Criterion and construct validity}

Total scores on the MARS had significant correlation with 'nonadherence' $(\rho=0.4 ; p<0.001)$, but not 'adherence' $(\rho=0.09 ; p=0.14)$. When TABS and MARS were subjected to principal components analysis together, all the items in MARS along with 'nonadherence' were grouped together as first component, while the four items in 'adherence' were grouped into the second component. The relationship between 'nonadherence' and the item on deciding to miss out a dose was significant $(\rho=0.29$; $p<0.001)$. The item on forgetting to take medicine had significant negative correlation with 'adherence' $(\rho=-0.13 ; p=0.04)$. The correlations between the MARS and the various subscales in the BBQ were in the expected direction (Table 8). The correlations between subscales from the same sections of the BBQ were either lacking or minor. These findings confirm the criterion and construct validities of the various BBQ sub-scales.

\subsection{Incremental validity}

A total of 253 patients answered all the items on both MARS and TABS. The MARS detected nonadherence in 154 of these patients. 'Nonadherence' alone detected adherence issues in 148 of the 154 patients; the six patients left undetected had scores $\geq 22$ on the MARS. The TABS ('adherence' and 'nonadherence' together) detected nonadherence in all except three of these 154 patients; the three patients who had aberrant scores on the TABS had high adherence scores reported on the MARS (MARS score $\geq 23$ ). Furthermore, the TABS detected nonadherence in an additional 92 respondents who had reported perfect
Table 9

Internal consistency of the subscales in two samples

\begin{tabular}{lll}
\hline $\begin{array}{l}\text { Domain/sub-scale } \\
\text { (number of items) }\end{array}$ & $\begin{array}{l}\text { Respiratory support } \\
\text { group patients } \\
(n=131)\end{array}$ & $\begin{array}{l}\text { Pulmonary } \\
\text { rehabilitation } \\
\text { patients }(n=145)\end{array}$ \\
\hline Confidence (9) & 0.82 & 0.80 \\
Concerns (5) & 0.44 & 0.47 \\
Satisfaction (3) & 0.86 & 0.84 \\
Disappointment (5) & 0.47 & 0.53 \\
Adherence (4) & 0.82 & 0.76 \\
Nonadherence (4) & 0.56 & 0.57 \\
\hline
\end{tabular}

adherence on the MARS, confirming the incremental validity of TABS. The median total scores on the MARS, 'adherence', and 'nonadherence' among the study participants were 24,19 and 8, respectively.

\subsection{Reliability}

Of the 20 patients who were sent a second questionnaire, $15(75 \%)$ returned the completed questionnaire. The testretest reliabilities (temporal stabilities) of the various subscales in the BBQ were: confidence, 0.62; concerns, 0.85; satisfaction, 0.94; disappointment, 0.86; nonadherence, 0.78; adherence, 0.91. The MARS had a test-retest reliability of 0.75 . The reliabilities of the various subscales in the BBQ for the patient support group sample $(n=131)$ and the pulmonary rehabilitation sample $(n=145)$ are given in Table 9.

\section{Discussion and conclusion}

\subsection{Discussion}

The BBQ, a patient self-administered tool for screening adherence behaviour and related health beliefs and experiences in patients with chronic ailments has been developed and validated. It incorporates two sub-scales each on health beliefs, experiences, and behaviour. The section on behaviour, TABS, by itself is a useful tool for measuring patient adherence. Items in the BBQ and the TABS were carefully chosen and worded to make them suitable for measuring patient beliefs, experiences and behaviour with 
regard to disease management in the broader sense, not just drug therapy. Multiple comorbidities are common among COPD patients, who are known to have more chronic medical conditions than other patient groups [38-41]. The prevalence of comorbidities in the validation sample and their use of multiple medications support BBQ's potential applications in patients with various chronic disease conditions.

An exploratory approach, similar to that used in the development of other scales [22,30], was used in generating the item pool for the BBQ. This ensured high credibility and face validity of each item. Unlike some questionnaires [34], the items in the BBQ were carefully worded and subjective words that could lead to responder bias have been avoided. The sample used to validate the BBQ and the TABS was of an adequate size [36] being much larger than those used in the development of some previous adherence instruments [18-20,22,24]. The MARS scores of the respondents suggest that the sample used for testing the new instrument had sufficiently well distributed adherence as measured by a currently accepted method. Similarities in the reliability observed in two patient groups for all sections of the BBQ confirm its stability across various clinical settings.

Patient beliefs about health and treatment are influenced by social and cultural factors. In developing the BBQ, the intention was to develop a clinically useful, simple, userfriendly, socially and culturally relevant, patient selfadministered instrument that covers the various aspects of adherence in adequate depth, rather than a lengthy questionnaire that measures every aspect in the theoretical framework in greater detail. Questionnaires based purely on psychosocial theories and/or without input from the target population, are likely to impose the researchers' views on the study subjects. Of the various theories and models on health behaviours, the Becker-Maiman model was consistent with the themes identified from the interviews and was hence chosen as the theoretical framework for developing the BBQ. However, sections on beliefs and experiences of the BBQ have several items that are representative of the components of some of the other existing cognitive models for predicting nonadherence. The BBQ encompasses the components-'expectation for treatment effectiveness' and 'cues to action' of the Health Belief Model and the 'internal' and the 'external' (powerful others) dimensions of the Health Locus of Control theory.

The need for at least two constructs in adherence screening measures is well recognised [21,34]. The items used in the TABS have been developed based on common adherence issues experienced by a sample of chronically ill patients and cover domains, judged by experts, to be important in adherence screening. When used with actual patients, they endorsed these items, leading to higher scores and the detection of nonadherence that would have been missed had only the MARS been used. The presence of more items and facets pertaining to adherence in the
TABS than the MARS might account for the modest and poor correlations between the subscales in the TABS and the MARS. Principal components analysis on all the items in the TABS and MARS further confirms the presence of multiple constructs of adherence in the TABS and its discriminant validity. Self-reports of adherence could be an overestimation and are often regarded as unreliable; however, people who report nonadherence tell the truth $[15,21,42]$. Thus, the incremental validity of the TABS in relation to the MARS confirms its advantage as a method for screening adherence.

The relatively poor internal consistencies of the domains 'concerns' and 'disappointment' could be attributed to the smaller number of items in those subscales and, possibly, the greater inherent heterogeneity of nonadherence. It is also possible that the respondents attempted to answer some of the negatively worded items in these subscales in a socially acceptable manner, affecting their correlations with the rest of the items in the component. Nevertheless, items with poor item-toscale correlations are often retained in a scale if they are considered important to the construct of the scale and/or the removal of those items has only a small impact on the internal consistency of the scale $[23,43]$. Some of the interviewees complained that certain medications (nonprescription items) were unaffordable, the reason for which the item 'financial difficulties limit my access to the best health care' was included in the BBQ. The differences in 'eligibility versus affordability' among the respondents might account for the poor inter-item correlation for this item. Financial limitations are rarely an impediment for access to optimal healthcare for most Australians due to the health care system, where medications are subsidised and care in public hospitals is free. However, this would be an important item in patient populations where treatment is not subsidised. The item 'I get confused about my medications' might be irrelevant in patients with good cognitive status, but is a very useful item for the elderly, especially those with complex medication regimens and those with cognitive impairment. The poor item-total correlation for this item might have resulted from the variability of the cognitive status of the respondents.

Alpha internal consistencies greater than 0.60 are regarded as desirable for psychometric scales [36]. It must be appreciated that alpha is a measure of internal consistency. Its value is determined by the number of items in a scale and their average intercorrelation [44]. However, alpha represents the lower bound of test reliability [45]. Thus, high values of alpha are informative and reassuring while low values are ambiguous. Actual test reliability (the correlation between the observed and the true score) may be much higher than the internal consistency of the scale. Testretest data may prove important in establishing scale reliability. The test-retest reliabilities of the various subscales in the BBQ ranged between 0.62 and 0.94 , suggesting 
that the scales are highly repeatable and thus adequately reliable.

It is likely that patients who responded to the $\mathrm{BBQ}$ were highly motivated, health conscious and more adherent to management recommendations than nonrespondents. It is also possible that they may have different health beliefs, experiences and behaviours compared to nonrespondents. The clinical and demographic features of the nonrespondents could not be matched with the respondents due to the anonymous nature of the questionnaire. However, the TABS detected nonadherence in more than one-half of the study subjects suggesting the appropriateness of the sample used for validating the questionnaire.

When developing the BBQ, the number of items representing the various themes identified from the interviews was based on the scope of the themes. No item corresponding to the theme 'emotional' was included in the $\mathrm{BBQ}$, assuming that it has little impact on chronic medication use; however, it is one of the components in Leventhal's Self-regulatory Model [7]. Though great care was taken to avoid confusing terms in the BBQ, the term 'push' in the item 'I push myself to follow the instructions of my doctors' in 'adherence' was later found to be ambiguous, being interpreted as either 'strive' or 'struggle'. This item had the least inter-item correlation in 'adherence', which might have been the result of such differences in interpretation. It is recommended that this item is reworded as 'I strive to follow the instructions of my doctors'.

Patient self-reports were relied upon for establishing the validity of the $B B Q$, though other researchers have tested the validity of adherence questionnaires against electronic monitoring, at least in smaller samples [18,21]. No objective measurements were possible to confirm the findings due to the cross-sectional design of the study, anonymous nature of the questionnaire, feasibility and patient privacy issues. At the time of development, the nature of the encompassing domains in the beliefs and experiences sections of the BBQ was not known. Hence, other measures (scales) were not used concurrently to evaluate their criterion validity. However, the correlations between the subscales in the BBQ and the MARS were as expected, supporting their construct validity. Testing the reliability and validity of the BBQ and the TABS against objective or direct measures in other patient populations would be valuable. Nevertheless, all the items in the BBQ have established face and content validity, satisfactory reliability and stability over time and in different populations.

\subsection{Conclusion}

The validity, reliability and utility of the BBQ, a patient self-administered tool for assessing the health beliefs and experiences pertaining to nonadherent behaviour and for identifying patients exhibiting suboptimal adherence, were tested in an adequately large sample. The TABS is a subscale of the BBQ that screens both intentional and unintentional nonadherence to pharmacological and nonpharmacological disease management. The BBQ and the TABS have potential applications in both clinical practice and research.

\subsection{Practice implications}

The BBQ will be useful to identify reasons behind intentional and unintentional nonadherence to both pharmacologic and non-pharmacologic management in patients with various chronic diseases. It could be employed for screening adherence during patient visits to outpatient clinics or health care professionals' ambulatory visits. The TABS measures both intentional and unintentional deviations from recommended pharmacological and non-pharmacological management in separate sub-scales with equal emphasis. Based on the median scores on the MARS, 'adherence' and 'nonadherence' in the study population, we provisionally recommend health professionals to target patients with 'adherence' scores less than 19 and 'nonadherence' scores above 8 for adherence interventions. Adherence and nonadherence could be measured as a continuous variable by converting TABS scores into ratios of the total score. Adherence could also be classified into high and low based on distribution of scores on the TABS.

TABS is unique and possesses several advantages over the existing tools for studying adherence. Separate measures for intentional and unintentional nonadherence are essential, especially when regression is used to determine the predictors of nonadherence, as the reasons behind these two types of nonadherence and the strategies for addressing them are distinct. The use of terms such as 'medicine' and 'pills' in some of the adherence tools limit their use in screening nonadherence to pharmacologic management, mainly to conventional dosage forms. Contrasting other adherence tools such as Morisky's scale [16] and the BMQ [18], judicious wording of the items in the TABS pertaining to treatment adherence allows the screening of both underutilization and overutilisation. The TABS is brief and could be completed by patients in a short time period making it a more practical tool than some other measures of adherence $[18,19]$.

\section{Acknowledgements}

This study was funded by the 2002 Novartis Grant of the Society of Hospital Pharmacists of Australia. We are grateful to the leaders of the respiratory groups and coordinator of the pulmonary rehabilitation centre for their help in patient recruitment. The authors acknowledge Prof. Robert Horne, Centre for Health Care Research, University of Brighton, for permission to use the MARS in this study. 
We thank the patients and health professionals who helped at various stages in the development and validation of the questionnaire. Johnson George was receiving a Monash Graduate Scholarship and a Monash International Postgraduate Research Scholarship at the time of the study and was supported by Monash University Postgraduate Publication Award for writing up this manuscript. This work was presented at the Eighth World Congress on Clinical Pharmacology and Therapeutics, 1-8 August 2004, Brisbane and the Australasian Pharmaceutical Science Association's Annual Conference, 4-7 December 2004, Melbourne.

\section{References}

[1] Kravitz RL, Melnikow J. Medical adherence research: time for a change in direction? Med Care 2004;42:197-9.

[2] Sackett DL, Snow JC. The magnitude of compliance and noncompliance. In: Haynes RB, Taylor DW, Sackett DL, editors. Compliance in healthcare. Baltimore: John Hopkins University Press; 1979 . p. 11-22.

[3] Burke LE, Dunbar-Jacob J. Adherence to medication, diet, and activity recommendations: from assessment to maintenance. J Cardiovasc Nurs 1995;9:62-79.

[4] Mellins RB, Evans D, Zimmerman B, Clark NM. Patient compliance. Are we wasting our time and don't know it? Am Rev Respir Dis 1992;146:1376-7.

[5] Rosenstock I. The health belief model and preventative health behaviour. Health Educ Monogr 1974;1974:354-86.

[6] Rotter J. Generalized expectancies for internal versus external control of reinforcements. Psychol Monit 1966;80 (Whole No. 609).

[7] Leventhal H, Meyer D, Narenz D. The common sense representation of illness danger. In: Rachman S, editor. Contributions to medical psychology. Oxford: Pergamon Press; 1980.

[8] Medicines partnership: from compliance to concordance. Medicines Partnership Task Force; 2002.

[9] Becker MH, Maiman LA. Sociobehavioral determinants of compliance with health and medical care recommendations. Med Care 1975;13:10-24.

[10] Dolce JJ, Crisp C, Manzella B, Richards JM, Hardin JM, Bailey WC. Medication adherence patterns in chronic obstructive pulmonary disease. Chest 1991;99:837-41.

[11] Rand CS, Nides M, Cowles MK, Wise RA, Connett J. Long-term metered-dose inhaler adherence in a clinical trial. The Lung Health Study Research Group. Am J Respir Crit Care Med 1995;152:580-8.

[12] Nides MA, Tashkin DP, Simmons MS, Wise RA, Li VC, Rand CS. Improving inhaler adherence in a clinical trial through the use of the nebulizer chronolog. Chest 1993;104:501-7.

[13] Horne R, Weinman J. Patients' beliefs about prescribed medicines and their role in adherence to treatment in chronic physical illness. J Psychosom Res 1999;47:555-67.

[14] Turner BJ, Hecht FM. Improving on a coin toss to predict patient adherence to medications. Ann Intern Med 2001;134: 1004-6.

[15] Inui TS, Carter WB, Pecoraro RE. Screening for noncompliance among patients with hypertension: is self-report the best available measure? Med Care 1981;19:1061-4.

[16] Morisky DE, Green LW, Levine DM. Concurrent and predictive validity of a self-reported measure of medication adherence. Med Care 1986;24:67-74.

[17] Horne R. The medication adherence report scale United Kingdom: University of Brighton; 2004.
[18] Svarstad BL, Chewning BA, Sleath BL, Claesson C. The brief medication questionnaire: a tool for screening patient adherence and barriers to adherence. Patient Educ Couns 1999;37: 113-24.

[19] Kennedy SB. Developing a self-administered tool to predict adherence to antiretroviral therapy: design, method, and objectives. AIDS Patient Care STDS 2000;14:309-16.

[20] Chesney MA, Ickovics JR, Chambers DB, Gifford AL, Neidig J, Zwickl B, Wu AW. Self-reported adherence to antiretroviral medications among participants in HIV clinical trials: the AACTG adherence instruments. Patient Care Committee and Adherence Working Group of the Outcomes Committee of the Adult AIDS Clinical Trials Group (AACTG). AIDS Care 2000;12:255-66.

[21] Choo PW, Rand CS, Inui TS, Lee ML, Cain E, Cordeiro-Breault M, Canning C, Platt R. Validation of patient reports, automated pharmacy records, and pill counts with electronic monitoring of adherence to antihypertensive therapy. Med Care 1999;37:846-57.

[22] Ogedegbe G, Mancuso CA, Allegrante JP, Charlson ME. Development and evaluation of a medication adherence self-efficacy scale in hypertensive African-American patients. J Clin Epidemiol 2003;56: 520-9.

[23] Hernandez CA. The development and pilot testing of the diabetes activities questionnaire (TDAQ): an instrument to measure adherence to the diabetes regimen. Appl Nurs Res 1997;10:202-11.

[24] Thompson K, Kulkarni J, Sergejew AA. Reliability and validity of a new medication adherence rating scale (MARS) for the psychoses. Schizophr Res 2000;42:241-7.

[25] Hogan TP, Awad AG, Eastwood R. A self-report scale predictive of drug compliance in schizophrenics: reliability and discriminative validity. Psychol Med 1983;13:177-83.

[26] Duong M, Piroth L, Grappin M, Forte F, Peytavin G, Buisson M, Chavanet $\mathrm{P}$, Portier $\mathrm{H}$. Evaluation of the patient medication adherence questionnaire as a tool for self-reported adherence assessment in HIVinfected patients on antiretroviral regimens. HIV Clin Trials 2001;2: $128-35$.

[27] DiMatteo MR, Hays RD, Gritz ER, Bastani R, Crane L, Elashoff R, Ganz P, Heber D, McCarthy W, Marcus A. Patient adherence to cancer control regimens: scale development and initial validation. Psychol Assess 1993;5:102-12.

[28] DiMatteo MR, Hays RD, Sherbourne CD. Adherence to cancer regimens: implications for treating the older patient. Oncology (Huntingt) 1992;6:50-7.

[29] Weinman J, Petrie KJ, Moss-Morris R, Horne R. The illness perception questionnaire: a new method for assessing the cognitive representation of illness. Psychol Health 1996;11:431-45.

[30] Horne R, Weinman J, Hankins M. The beliefs about medicines questionnaire: the development and evaluation of a method for assessing the cognitive representation of medication. Psychol Health 1999;14:1-24.

[31] Horne R. Representations of medications and treatment: advances in theory and measurement. In: Petrie KJ, Weinman JA, editors. Perceptions of health and illness. London: Harwood Academic; 1997. p. 15588.

[32] Marinker M, Blenkinsopp A, Bond C, Briten N, Feely M, George C. From compliance to concordance: achieving shared goals in medicine taking London: Royal Pharmaceutical Society of Great Britain; 1997 .

[33] Weintraub M. Compliance in the elderly. Clin Geriatr Med 1990;6: 445-52.

[34] Pratt RJ, Robinson N, Loveday HP, Pellowe CM, Franks PJ, Hankins M, Loveday C. Adherence to antiretroviral therapy: appropriate use of self-reporting in clinical practice. HIV Clin Trials 2001;2:146-59.

[35] Briggs SR, Cheek JM. The role of factor analysis in the development and evaluation of personality scales. J Personality 1986;54:106-48.

[36] DeVellis RF. Scale development: theory and applications California: SAGE Publications; 1991. 
[37] George J, Ioannides-Demos LL, Santamaria NM, Kong DC, Stewart $\mathrm{K}$. Use of complementary and alternative medicines by patients with chronic obstructive pulmonary disease. Med J Aust 2004;181:248-51.

[38] Incalzi RA, Pedone C, Onder G, Pahor M, Carbonin PU. Predicting length of stay of older patients with exacerbated chronic obstructive pulmonary disease. Aging (Milano) 2001;13:49-57.

[39] Mapel DW, Picchi MA, Hurley JS, Frost FJ, Petersen HV, Mapel VM, Coultas DB. Utilization in COPD: patient characteristics and diagnostic evaluation. Chest 2000;117:346S-53S.

[40] Confalonieri M, Gorini M, Ambrosino N, Mollica C, Corrado A. Respiratory intensive care units in Italy: a national census and prospective cohort study. Thorax 2001;56:373-8.
[41] Ball P, Harris JM, Lowson D, Tillotson G, Wilson R. Acute infective exacerbations of chronic bronchitis. Quat J Med 1995;88:61-8.

[42] Haynes RB, Taylor DW, Sackett DL, Gibson ES, Bernholz CD, Mukherjee J. Can simple clinical measurements detect patient noncompliance? Hypertension 1980;2:757-64.

[43] Simpson SH, Johnson JA, Farris KB, Tsuyuki RT. Development and validation of a survey to assess barriers to drug use in patients with chronic heart failure. Pharmacotherapy 2002;22:1163-72.

[44] Grayson DA. Limitations on the use of scales in psychiatric research. Aust N Z J Psychiatry 1988;22:99-108.

[45] Cronbach LJ. Coefficient alpha and the internal structure of tests. Psychometrika 1951;16:297-334. 